GUÍAS DE PRÁCTICAS

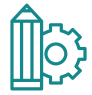

GUÍA DE PRESENTACIÓN DE CASOS CLÍNICOS DE ODONTOPEDIATRÍA

Johanna Carolina Arias Ramírez

Universidad Cooperativa de Colombia

Sede Villavicencio
Documentos de docencia | Course Work coursework.ucc.edu.co

N. ${ }^{\circ} 30$, noviembre de 2016

\title{
NOTA LEGAL
}

El presente documento de trabajo ha sido incluido dentro de nuestro repositorio de literatura gris por solicitud del autor, con fines informativos, educativos o académicos. Asimismo, los argumentos, datos y análisis incluidos en el texto son responsabilidad absoluta del autor y no representan la opinión del Fondo Editorial o de la Universidad. 


\section{ACERCA DEL AUTOR}

Johanna Carolina Arias Ramírez, estomatóloga pediatra y ortopedista maxilar, profesora instructora del programa de Odontología, Universidad Cooperativa de Colombia, sede Villavicencio, Meta, Colombia.

Correo electrónico: johanna.ariasr@campusucc.edu.co

\section{CóMO CITAR ESTE DOCUMENTO}

Arias-Ramírez JC. Guía de presentación de casos clínicos de odontopediatría. (Documento de docencia Nº 30). Bogotá: Ediciones Universidad Cooperativa de Colombia, 2016. Doi https://doi.org/10.16925/greylit.1931

Este documento puede ser consultado, descargado o reproducido desde nuestro repositorio de documentos de trabajo (http:// coursework.ucc.edu.co) para uso de sus contenidos, bajo la licencia de Creative Commons Reconocimiento-No Comercial-Sin Obra Derivada 4.0 Internacional. http://creativecommons.org/ licenses/by-nc-nd/4.0/ 


\section{TABLA DE CONTENIDO}

$\begin{array}{ll}\text { INTRODUCCIÓN } & 6\end{array}$

Objetivo general 6

$\begin{array}{ll}\text { Recomendaciones } & 6\end{array}$

PROCEDIMIENTOS PARA PRESENTAR UN CASO CLÍNICO 7

1. Datos personales 7

2. Motivo de consulta e historia de la afección presente 7

2.1. Motivo de consulta 7

2.2. Historia de la afección presente

3. Antecedentes personales

4. Antecedentes psicosociales 8

5. Antecedentes familiares 9

5.1. Médicos 9

5.2. Odontológicos 9

6. Revisión por sistemas 10

$\begin{array}{ll}\text { 7. Examen extraoral } & 10\end{array}$

7.1. Análisis frontal 10

7.2. Análisis sagital 11

7.3. Análisis vertical 11

8. Examen intraoral 11

9. Control de higiene oral 12

10. Odontograma 13

11. Hallazgos dentales: criterios ICDAS 13

11.1. Otros hallazgos dentales 14

12. Valoración de riesgo individual de caries con riesgograma 15

13. Análisis funcional 17

14. Análisis radiográfico 17

14.1. Análisis radiografía periapical 17

14.2. Análisis radiografía coronal o de aleta de mordida 17

14.3. Análisis radiografía panorámica 18

$\begin{array}{ll}\text { 14.4. Análisis radiografía lateral de cráneo } & 18\end{array}$

15. Análisis de dentición mixta 19

16. Diagnósticos 20

17. Pronóstico 20

18. Plan de tratamiento 20

19. Revisión del tema 21

Referencias 22 


\section{ÍNDICE DE FIGURAS}

$\begin{array}{ll}\text { Figura 1. Datos personales } & 7\end{array}$

Figura 2. Motivo de consulta e historia de la afección presente $\quad 7$

Figura 3. Antecedentes personales $\quad 7$

Figura 4. Antecedentes familiares 10

Figura 5. Índice cefálico e índice facial $\quad 10$

Figura 6. Análisis frontal 10

Figura 7. Análisis sagital 11

Figura 8. Análisis vertical 11

Figura 9. Examen de tejidos blandos 11

Figura 10. Control de higiene oral 12

Figura 11. Índice de placa bacteriana de Silness y Löe modificado 12

Figura 12. Porcentaje de placa bacteriana según número de superficies con código 12

Figura 13. Odontograma 13

Figura 14. Sistema Internacional para la Detección y Valoración de Caries Dental (ICDAS) 13

Figura 15. Hallazgos dentales arco superior 14

Figura 16. Hallazgos dentales arco inferior $\quad 14$

Figura 17. Análisis intraarco superior $\quad 14$

Figura 18. Análisis intraarco inferior 14

Figura 19. Análisis interarco derecho 15

Figura 20. Análisis interarco izquierdo 15

Figura 21. Análisis oclusión de frente 15

Figura 22. Formato de riesgograma 16

Figura 23. Nivel de riesgo individual de caries 16

Figura 24. Análisis radiografía periapical 17

Figura 25. Análisis radiografía coronal 17

$\begin{array}{lr}\text { Figura 26. Radiografía panorámica } & 18\end{array}$

Figura 27. Análisis cefalométrico de Steiner 18

Figura 28. Análisis cefalométrico de McNamara 18

Figura 29. Tabla de predicción de tamaño mesiodistal de caninos y premolares superiores 19

Figura 30. Tabla de predicción de tamaño mesiodistal de caninos y premolares inferiores 20

$\begin{array}{ll}\text { Figura 31. Manejo de factores de riesgo } & 21\end{array}$

\section{ÍNDICE DE TABLAS}

Tabla 1. Convenciones del familiograma 8

Tabla 2. Estructura familiar 8

Tabla 3. Variables estratificación social 9

Tabla 4. Estratificación social según puntaje 9

Tabla 5. Revisión por sistemas $\quad 10$

Tabla 6. Convenciones del odontograma 13

Tabla 7. Análisis funcional del sistema estomatognático 17

Tabla 8. Hoja de diagnósticos $\quad 20$

Tabla 9. Categorización de plan de tratamiento según prioridad 21 


\section{GUÍA DE PRESENTACIÓN DE CASOS}

Johanna Carolina Arias Ramírez

\section{RESUMEN}

El caso clínico, según lo definido por la Real Academia de Medicina, es el método por el cual se describen, de manera ordenada y detallada, los acontecimientos que ocurren en un paciente durante el curso de una enfermedad como los signos y síntomas, el diagnóstico, el tratamiento y el seguimiento o mantenimiento de dichas intervenciones. El objetivo de la presentación de un caso clínico es la construcción de conocimiento mediante la argumentación y discusión con pares acerca del diagnóstico o tratamiento particular de un paciente, que ha sido atendido por un estudiante según su nivel de formación y que ha sido presentado ante un público de diversos niveles de complejidad clínica. Durante el desarrollo de la presentación, el estudiante deberá seguir los lineamientos técnicos y éticos establecidos en las guías y protocolos clínicos de la Facultad de Odontología para no incurrir en faltas. La guía contempla, grosso modo, dos aspectos importantes: el primero es la descripción detallada del caso con sus antecedentes y diagnósticos (incluidos los exámenes de apoyo y la lectura de estos), el pronóstico y el plan de tratamiento. El segundo aspecto se basará en la revisión del tema con soporte de artículos científicos para dar explicación al aspecto relevante del caso y con ello generar una discusión y nuevo conocimiento.

Palabras clave: caso, cefalometría, diagnóstico, guía, odontología pediátrica, tratamiento. 


\section{INTRODUCCIÓN}

La presentación de casos clínicos en el área de odontopediatría permite, tanto a estudiantes como a tutores, correlacionar las ciencias básicas con la práctica clínica que lleve a la generación de un diagnóstico asertivo según el motivo de consulta del paciente. A esto se suma la posibilidad de brindar el tratamiento ideal al paciente pediátrico de acuerdo con las últimas tendencias científicas, sin olvidar el contexto biopsicosocial del niño; es decir que la Odontopediatría como ciencia odontológica siempre está encaminada a una atención integral de los pacientes.

Esta guía pretende generar nuevo conocimiento tanto en el diagnóstico como en el manejo integral, interdisciplinario y multidisciplinario del paciente pediátrico, en procura de mejorar su calidad de vida resolviendo sus necesidades en salud oral, todo esto con un sustento científico.

\section{OBJETIVO GENERAL}

Brindar a los estudiantes que cursan las Clínicas del Niño I, II y iII de la Facultad de Odontología de la Universidad Cooperativa de Colombia, sede Villavicencio, una herramienta para presentar, de manera estructurada y lógica, un caso clínico en el que se demuestre a través de un sustento científico un fenómeno relevante de sus pacientes pediátricos.

\section{RECOMENDACIONES}

- La presentación del caso clínico debe realizarse con base en la plantilla institucional.

- Debe usarse un lenguaje técnico-científico tanto en las diapositivas como en la presentación oral.

- Las fotografías intraorales deben evidenciar el antes y después del tratamiento para identificar el proceso.

- Se aconseja preparar con antelación el caso clínico para evitar la necesidad de leer las diapositivas en plena presentación.

- La revisión del tema se debe soportar con artículos científicos de alta evidencia académica, como los que se pueden encontrar en las bases de datos de la Universidad. No se tendrán en cuenta artículos que hayan sido descargados de motores de búsqueda como Google o Bing, pues carecen de rigurosidad científica. 
PROCEDIMIENTOS PARA

PRESENTAR UN CASO CLÍNICO

\section{DATOS PERSONALES}

A continuación, se deben registrar los datos de identificación del paciente:

- Nombre completo

- Identificación (NUIP o T.I.) según sea el caso.

- $\quad$ Edad (años o meses)

- Género

- Fecha y lugar de nacimiento

- Procedencia

Esta diapositiva debe ir acompañada por una fotografía de frente del paciente con una franja negra que oculte los ojos (ver figura 1).

\section{IDENTIFICACIÓN PERSONAL}

- Nombre:

- Identificación:

- Edad:

- Genero:

- Fecha y lugar de nacimiento:

- Procedencia:

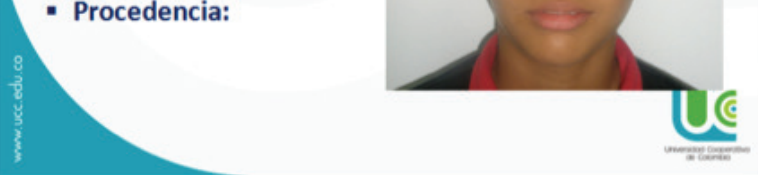

FIGURA 1. Datos personales

Fuente: elaboración propia

\section{MOTIVO DE CONSULTA E HISTORIA DE LA AFECCIÓN PRESENTE}

\subsection{Motivo de consulta}

Registre entre comillas, con las propias palabras del paciente o el acudiente, el motivo por el cual asiste al servicio de odontología pediátrica.

\subsection{Historia de la afección presente}

En este ítem se realiza una interpretación técnica del motivo de consulta del paciente o de lo referido por el acudiente.

Los dos últimos ítems deben ser consignados en una misma diapositiva, tal como lo muestra la figura 2.

- MOTIVO DE CONSULTA: “ Mis dientes de abajo los tengo muy torcidos"

- HISTORIA DE LA AFECCIÓN PRESENTE: Paciente de género masculino de 10 años de edad, asiste a consulta en compañía de la mamá, por presentar apiñamiento de los anteroinferiores.
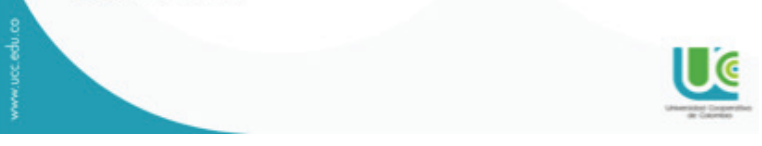

FIGURA 2. Motivo de consulta e historia de la afección presente Fuente: elaboración propia

\section{ANTECEDENTES PERSONALES}

En esta diapositiva, en una tabla como lo presenta la figura 3, registre aquellos eventos traumáticos, quirúrgicos u hospitalizaciones que haya presentado el paciente desde su nacimiento. Anote edad del niño al momento de sufrir el evento. Si el paciente no presenta ninguno, escriba "No refiere de importancia".

\section{ANTECEDENTES PERSONALES}

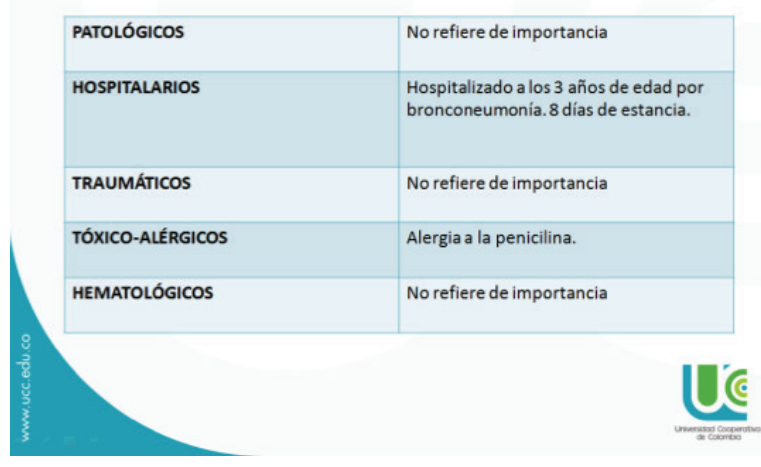

FIGURA 3. Antecedentes personales

Fuente: elaboración propia 


\section{ANTECEDENTES PSICOSOCIALES}

En este aparte (tabla 1), se registra en un familiograma [1] el núcleo familiar del paciente con las siguientes convenciones:

TABLA 1. Convenciones del familiograma

\begin{tabular}{|l|l|}
\hline Elemento & Convención \\
\hline Hombre & \\
\hline Mujer & \\
\hline Fallecido & \\
\hline Paciente & \\
\hline Separaciónonio o unión libre & \\
\hline Convivencia bajo el mismo techo & \\
\hline
\end{tabular}

Fuente: [1]

En la evaluación psicosocial del niño es importante observar la funcionalidad de la familia con la cual convive, entendiendo que la familia es un sistema que provee recursos tanto materiales como cognitivos para que los niños crezcan en cuerpo y mente. Por lo anterior, la estructura familiar del niño debe señalarse de acuerdo con la tabla 2 que presenta la doctora Berger [2]:

Hay que mencionar aspectos como el estrato socioeconómico con base en el método Graffar-Méndez Castellano [3] para identificar los niveles de bienestar social de los niños. Para esto, se les hace un cuestionario a los padres (ver tabla 3) con el fin de obtener un puntaje según cada ítem y así clasificar por estratos a la familia (ver tabla 4). También hay que tener en cuenta antecedentes prenatales, perinatales y postnatales, experiencias previas odontológicas (si fueron positivas o negativas) y aspectos comportamentales (si es un niño cooperador, potencialmente cooperador o no cooperador).

TABLA 2. Estructura familiar

\begin{tabular}{|c|c|}
\hline \multicolumn{2}{|l|}{ Familias biparentales } \\
\hline Familia nuclear & $\begin{array}{l}\text { La familia nuclear consiste en } \\
\text { marido, mujer y sus respectivos } \\
\text { hijos. }\end{array}$ \\
\hline Familia de padrastros & $\begin{array}{l}\text { Los padres divorciados son propen- } \\
\text { sos a volver a casarse. Cuando los } \\
\text { hijos del matrimonio anterior con- } \\
\text { viven con la nueva pareja se deno- } \\
\text { mina familia de padrastros. }\end{array}$ \\
\hline Familia mezclada & $\begin{array}{l}\text { Es un tipo de familia de padrastros } \\
\text { que reúne a los hijos biológicos de } \\
\text { los matrimonios anteriores de los } \\
\text { esposos y a los hijos biológicos de } \\
\text { la nueva pareja. }\end{array}$ \\
\hline Familia adoptiva & $\begin{array}{l}\text { Parejas casadas estériles que } \\
\text { adoptan un hijo. }\end{array}$ \\
\hline Familia polígama & $\begin{array}{l}\text { En algunos países se considera } \\
\text { normal que un hombre tenga varias } \\
\text { esposas y cada una con sus hijos. } \\
\text { Esto se denomina familia polígama. }\end{array}$ \\
\hline \multicolumn{2}{|l|}{ Familias monoparentales } \\
\hline Madre soltera, no casada & $\begin{array}{l}\text { Muchos niños son hijos de madres } \\
\text { solteras que pueden tener o no } \\
\text { tener la intención de casarse algún } \\
\text { día. }\end{array}$ \\
\hline Madre soltera, divorciada & $\begin{array}{l}\text { Aunque muchos matrimonios ter- } \\
\text { minan en divorcio, muchas pare- } \\
\text { jas divorciadas no tienen hijos y } \\
\text { muchas otras vuelven a casarse. } \\
\text { Asimismo, muchas de las mujeres } \\
\text { divorciadas no tienen hijos que } \\
\text { vivan con ellas. }\end{array}$ \\
\hline $\begin{array}{l}\text { Padre soltero, divorciado o } \\
\text { no casado }\end{array}$ & $\begin{array}{l}\text { Cerca de uno de cada cinco padres } \\
\text { divorciados o no casados poseen la } \\
\text { custodia física de sus hijos. }\end{array}$ \\
\hline \multicolumn{2}{|l|}{ Otros tipos de familia } \\
\hline Familia extendida & $\begin{array}{l}\text { Muchos niños viven con sus abue- } \\
\text { los o y con uno o ambos padres. }\end{array}$ \\
\hline Abuelos solos & $\begin{array}{l}\text { Para muchos niños, sus "padres" } \\
\text { son sus abuelos, porque sus padres } \\
\text { biológicos han muerto o están inca- } \\
\text { pacitados para vivir con ellos. }\end{array}$ \\
\hline Familia homosexual & $\begin{array}{l}\text { Cuando un niño vive con una pareja } \\
\text { homosexual, es porque el padre que } \\
\text { posee la custodia tiene una pareja } \\
\text { homosexual. Determinada por leyes } \\
\text { según el país. }\end{array}$ \\
\hline Familia de acogida & $\begin{array}{l}\text { Es un tipo de familia temporal y los } \\
\text { niños se categorizan por su estruc- } \\
\text { tura familiar original. }\end{array}$ \\
\hline
\end{tabular}

Fuente: [2] 
TABLA 3. Variables estratificación social

\begin{tabular}{|c|c|c|}
\hline Variables & Puntaje & Ítems \\
\hline \multirow[t]{5}{*}{ 1. Profesión del jefe de familia } & 1 & $\begin{array}{l}\text { Profesión universitaria, financistas, banqueros, comerciantes, todos de alta productividad, } \\
\text { oficiales de las Fuerzas Armadas (si tienen un rango de educación superior). }\end{array}$ \\
\hline & 2 & Profesión técnica superior, medianos comerciantes o productores. \\
\hline & 3 & $\begin{array}{l}\text { Empleados sin profesión universitaria, con técnica media, pequeños comerciantes } 0 \\
\text { productores. }\end{array}$ \\
\hline & 4 & $\begin{array}{l}\text { Obreros especializados y parte de los trabajadores del sector informal (con primaria } \\
\text { completa). }\end{array}$ \\
\hline & 5 & $\begin{array}{l}\text { Obreros no especializados y otra parte del sector informal de la economía (sin primaria } \\
\text { completa). }\end{array}$ \\
\hline \multirow[t]{5}{*}{ 2. Nivel de instrucción de la madre } & 1 & Enseñanza universitaria o su equivalente. \\
\hline & 2 & Técnica superior completa, enseñanza secundaria completa, técnica media. \\
\hline & 3 & Enseñanza secundaria incompleta, técnica inferior. \\
\hline & 4 & Enseñanza primaria o alfabeta (con algún grado de instrucción primaria). \\
\hline & 5 & Analfabeta. \\
\hline \multirow{5}{*}{$\begin{array}{l}\text { 3. Principal fuente de ingreso de la } \\
\text { familia }\end{array}$} & 1 & Fortuna heredada o adquirida. \\
\hline & 2 & Ganancias o beneficios, honorarios profesionales. \\
\hline & 3 & Sueldo mensual. \\
\hline & 4 & Salario semanal, por día, entrada a destajo. \\
\hline & 5 & Donaciones de origen público o privado. \\
\hline \multirow[t]{5}{*}{ 4. Condiciones de alojamiento } & 1 & Viviendas con óptimas condiciones sanitarias en ambientes de gran lujo. \\
\hline & 2 & $\begin{array}{l}\text { Viviendas con óptimas condiciones sanitarias en ambientes con lujo sin exceso y suficientes } \\
\text { espacios. }\end{array}$ \\
\hline & 3 & $\begin{array}{l}\text { Viviendas con buenas condiciones sanitarias en espacios reducidos } 0 \text { no, pero siempre } \\
\text { menores que en las viviendas } 1 \text { y } 2 \text {. }\end{array}$ \\
\hline & 4 & $\begin{array}{l}\text { Viviendas con ambientes espaciosos o reducidos } y / 0 \text { con deficiencias en algunas condi- } \\
\text { ciones sanitarias. }\end{array}$ \\
\hline & 5 & Rancho o vivienda con condiciones sanitarias marcadamente inadecuadas. \\
\hline
\end{tabular}

Fuente: [4]

TABLA 4. Estratificación social según puntaje

\begin{tabular}{|l|l|}
\hline \multicolumn{1}{|c|}{ Estrato } & \multicolumn{1}{c|}{ Total de puntaje obtenido } \\
\hline Estrato 1 & $4,5,6$ \\
\hline Estrato 2 & $7,8,9$ \\
\hline Estrato 3 & $10,11,12$ \\
\hline Estrato 4 & $13,14,15,16$ \\
\hline Estrato 5 & $17,18,19,20$ \\
\hline
\end{tabular}

\section{Fuente: [4]}

Con base en lo anterior, presente en una diapositiva el resumen completo del estado psicosocial de su paciente.

\section{ANTECEDENTES FAMILIARES}

\subsection{Médicos}

Registre aquellas patologías sistémicas del núcleo familiar del menor que tienen alta frecuencia hereditaria como diabetes mellitus, cáncer o hipertensión u otras anomalías. Si no hay presencia de ningún tipo de patología sistémica escriba "Sin antecedentes".

\subsection{Odontológicos}

Registre aquellos diagnósticos orales que presenten manifestaciones hereditarias como prognatismo o retrognatismo de los maxilares, apiñamientos, dientes supernumerarios o agenesias dentales, entre otras anomalías. Si no hay presencia de algún tipo diagnóstico relevante, escriba "No refiere de importancia".

Como lo evidencia la figura 4, los antecedentes médicos y odontológicos familiares deben ser consignados en una misma diapositiva. 


\section{ANTECEDENTES FAMILIARES}

- Médicos: Abuelo materno Diabetes Mellitus Tipo 2, tía paterna Hipertiroidismo.

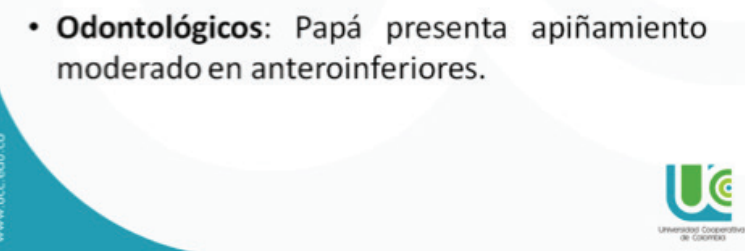

FIGURA 4. Antecedentes familiares

Fuente: elaboración propia

\section{REVISIÓN POR SISTEMAS}

Para este ítem presente en una diapositiva una tabla con aquellos antecedentes médicos personales del paciente que tengan relevancia clínica, teniendo en cuenta los de mayor frecuencia en la población pediátrica, así como se muestra en la tabla 5:

TABLA 5. Revisión por sistemas

\begin{tabular}{|c|c|}
\hline Cabeza y cuello & $\begin{array}{l}\text { Presencia de linfoadenopatías, describiendo la } \\
\text { cadena ganglionar afectada, tamaño del ganglio, } \\
\text { duro o no, movilidad. }\end{array}$ \\
\hline Cardiovascular & $\begin{array}{l}\text { Cardiopatías congénitas (CIA, Cıv, ductus arteri- } \\
\text { oso persistente, soplos, etc.). }\end{array}$ \\
\hline Respiratorio & $\begin{array}{l}\text { Rinitis, sinusitis, asma, bronquiolitis, neumonía, } \\
\text { etc. }\end{array}$ \\
\hline Gastrointestinal & $\begin{array}{l}\text { Aquí es importante mencionar la edad de control } \\
\text { del esfínter anal para determinar el adecuado } \\
\text { desarrollo del niño. Mencione las anomalías del } \\
\text { sistema. }\end{array}$ \\
\hline Genitourinario & $\begin{array}{l}\text { Aquí es importante mencionar la edad de control } \\
\text { del esfínter vesical para determinar el adecuado } \\
\text { desarrollo del niño. Mencione las anomalías del } \\
\text { sistema. }\end{array}$ \\
\hline Locomotor & $\begin{array}{l}\text { Mencione los hitos del desarrollo psicomotor } \\
\text { en meses (sostén cefálico, sedestación, gateo, } \\
\text { bipedestación), coordinación de la marcha. }\end{array}$ \\
\hline Nervioso & Epilepsia, síndromes. \\
\hline Endocrino & $\begin{array}{l}\text { Registre las principales anomalías de este } \\
\text { sistema, sobre todo lo relacionado con la hor- } \\
\text { mona del crecimiento y las tiroideas. }\end{array}$ \\
\hline Hematopoyético & $\begin{array}{l}\text { Presencia de discrasias sanguíneas (anemias, } \\
\text { hemofilia, púrpuras, etc.). }\end{array}$ \\
\hline Inmunológico & $\begin{array}{l}\text { Verifique si el niño cuenta con el esquema de } \\
\text { vacunación completo para la edad, si hay pres- } \\
\text { encia de alergias, enfermedades autoinmunes, } \\
\text { inmunodeficiencias, etc. }\end{array}$ \\
\hline Piel y anexos & $\begin{array}{l}\text { Si hay presencia de cicatrices, nevus (lunares) } \\
\text { u otro tipo de lesiones. Registre ubicación } \\
\text { anatómica, longitud y diámetro de la lesión. }\end{array}$ \\
\hline
\end{tabular}

\section{EXAMEN EXTRAORAL}

En diapositiva con fotografía de frente y de perfil derecho del paciente, presente los índices cefálico y facial según corresponda el caso (ver figura 5).

\section{EXAMEN EXTRAORAL}

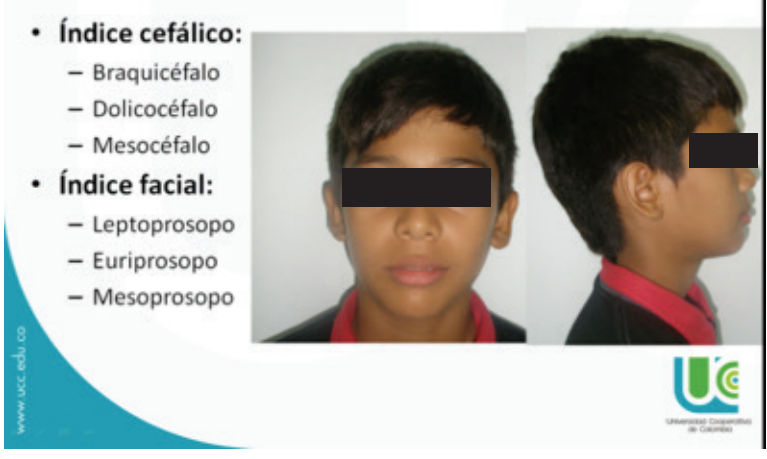

FIGURA 5. Índice cefálico e índice facial

Fuente: elaboración propia

\subsection{Análisis frontal}

En esta diapositiva presente en una fotografía de frente la línea media del paciente y las líneas de los quintos para observar si hay simetría transversal, si las líneas de los cantos internos coinciden con la anchura nasal, si la línea del iris coincide con las comisuras labiales y la proyección de las orejas. No olvide hacer mención de la competencia labial (ver figura 6).

\section{EXAMEN EXTRAORAL: Análisis Frontal}

- Simetría transversal:

- Anchura nasal:

- Anchura intercomisural:

- Proyección de las orejas:

- Sellado labial

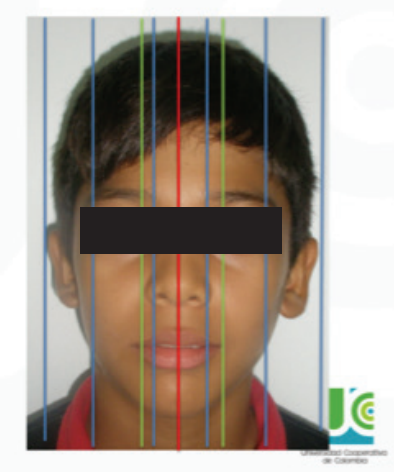

FIGURA 6. Análisis frontal

Fuente: elaboración propia 


\subsection{Análisis sagital}

En una fotografía de perfil trace las líneas en tejidos blandos según los puntos cefalométricos (Glabela-Subnasal-Pogonion) para determinar el perfil facial. A continuación, trace la Línea E de Ricketts (Pronasal-Pogonion) para determinar la posición de los labios; y el ángulo nasolabial para medir la inclinación de la columnela con respecto al labio superior [5] (ver figura 7).

\section{EXAMEN EXTRAORAL: Análisis Sagital}

- PERFIL:

- Ángulo nasolabial:

- Posición labial: Superior Inferior

- Tonicidad labial: Superior Inferior
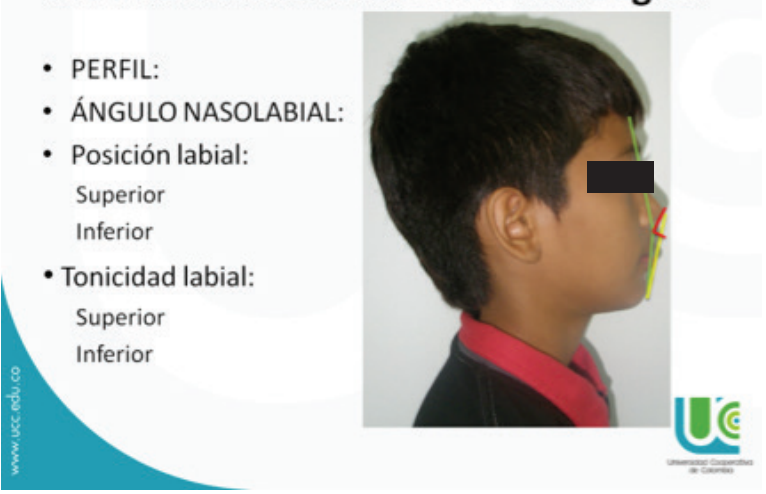

FIGURA ?. Análisis sagital

Fuente: elaboración propia

\subsection{Análisis vertical}

En una fotografía de frente, trace una línea que pase por la implantación más baja del cabello (trichion), una línea que pase por el punto glabela (sobre el perfil de tejidos blandos); otra línea que pase por el punto subnasal en la base de la nariz, y la última línea debe pasar por el punto mentón [6, 7]. Determine las medidas de cada tercio para verificar si existe o no proporcionalidad de la cara. Adicione una línea que pase por el punto más bajo del labio superior (estomion superior) para determinar la proporción del labio superior, que debe ser un tercio del tercio inferior de la cara (ver figura 8).

\section{EXAMEN EXTRAORAL: Análisis Vertical}

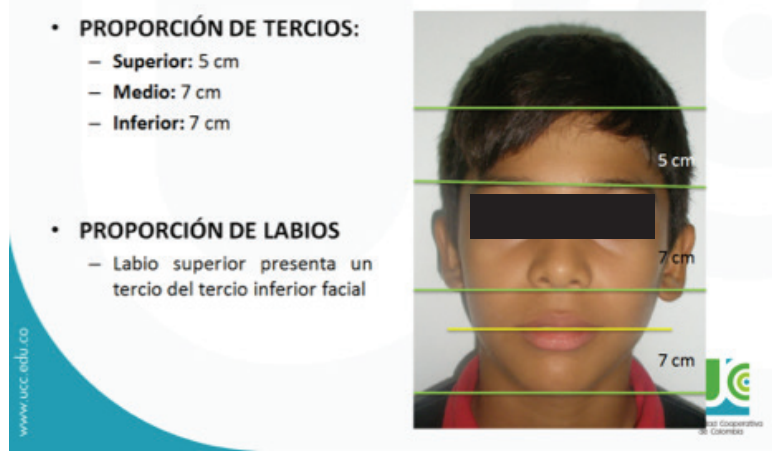

FIGURA 8. Análisis vertical

Fuente: elaboración propia

\section{EXAMEN INTRAORAL}

Para el examen intraoral presente en una diapositiva las fotografías del arco superior e inferior y señale en una tabla las anormalidades que halle en esta exploración de los tejidos blandos (encías, frenillo, paladar, piso de boca, lengua, orofaringe), tal como lo muestra la figura 9. De lo contrario, escriba "En normalidad" o "Aparentemente sano".

\section{EXAMEN INTRAORAL}

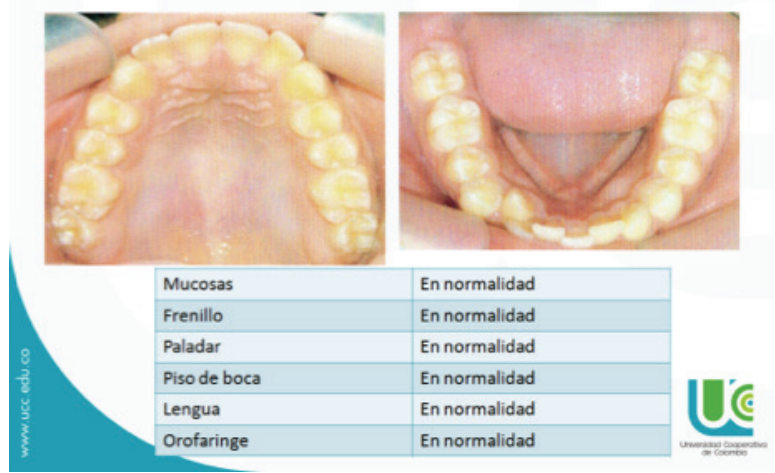

FIGURA 9. Examen de tejidos blandos

Fuente: elaboración propia 


\section{CONTROL DE HIGIENE ORAL}

En esta diapositiva (ver figura 10), presente el indice de placa bacteriana de O'Leary inicial de su paciente en comparación con los controles realizados durante el semestre para observar el progreso o retroceso de la higiene oral del niño. Durante la presentación hay que hacer mención de la técnica de cepillado y de los elementos de higiene oral que esté utilizando el paciente.

\section{CONTROL DE HIGIENE ORAL}

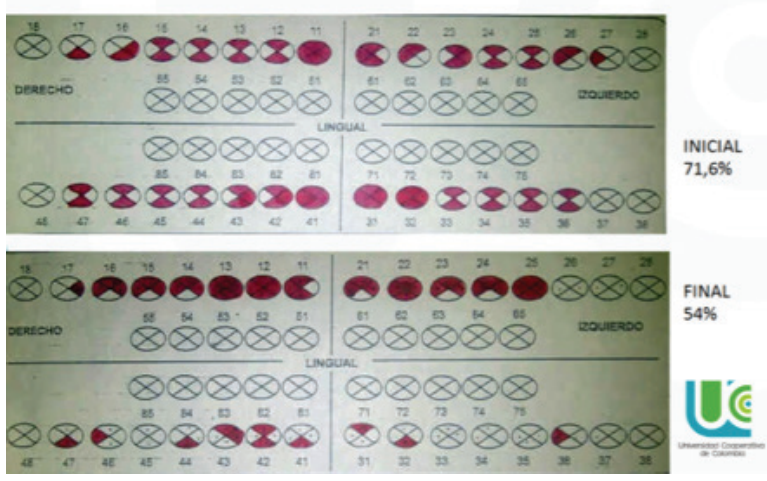

FIGURA 10. Control de higiene oral

Fuente: elaboración propia

En el control de higiene oral es importante registrar el índice de placa bacteriana visible de Silness y Löe modificado [8]. Esta herramienta después ayudará a realizar un registro de riesgo individual de caries del paciente a través del riesgograma. Este índice está basado en el grosor de placa bacteriana y lo relaciona con el tiempo que ha permanecido sobre las superficies dentales sin ser removida. No requiere del uso de revelador de placa.
Para iniciar la observación se utilizan siete dientes índices (últimos molares de cada cuadrante, 11 o 51, 23 o 63, 44 u 84), y luego se observa el grosor de placa por cada superficie dental vestibular (V), lingual/palatino (L/P), mesial (M), distal (D) y en los molares, además de la superficie oclusal (O), cuyo valor será consignado en una tabla (ver figura 11), siendo "1" placa gruesa evidente y "0" si no hay evidencia de placa.

Para calcular el resultado se cuenta el número de las superficies con valores "1" y se multiplica por 100 y luego se divide el valor por el número de superficies evaluadas (si están todos los dientes, serán 33 superficies). En la figura 12 se encuentra el porcentaje correspondiente según el número de superficies evaluadas con código "1" (solo sirve si se evaluaron 33 superficies; en caso contrario, debe realizar el cálculo).

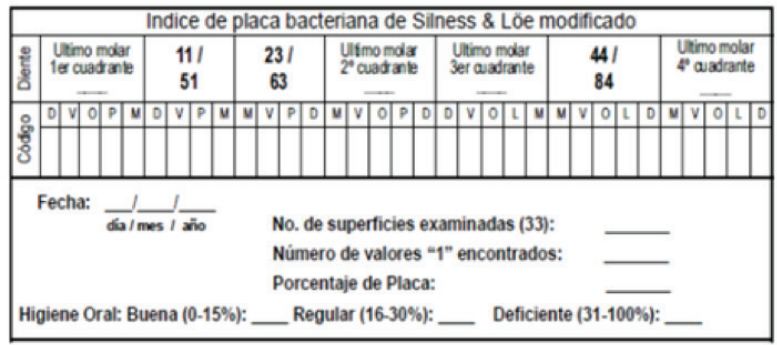

FIGURA 11. Índice de placa bacteriana de Silness y Löe modificado

Fuente: [8]

\begin{tabular}{|c|c|c|c|c|c|c|c|c|c|c|c|c|c|c|c|c|c|}
\hline \multicolumn{18}{|c|}{ Porcentaje de Placa Bacteriana según número de superficies con Codigo " 1 " } \\
\hline Ne devilow T' & 0 & 1 & 2 & 3 & 4 & s & 6 & 7 & 8 & ? & 10 & 11 & 12 & 13 & $\mathbf{u}$ & is & is \\
\hline Prontupe opdiviett & as & $\mathbf{s}$ & 6s & n & 125 & iss & ws & $21 \mathrm{~s}$ & 26 & $2 \pi$ & os & $\operatorname{ses}$ & ws & ns & as & es & es \\
\hline We devilowe T' & n & is & 10 & 20 & 21 & $n$ & 23 & 2a & 25 & 26 & $z$ & $\mathbf{a}$ & $x$ & $x$ & rt & $x$ & $x$ \\
\hline Proteip oqubiente & $5 \pi$ & ss & $\operatorname{sen}$ & 61s & GS & 6rs & os & ms & ws & $\pi$ & $\mathrm{m}$ & ass & $\cos$ & ins & is & $\mathbf{m}$ & $10 \mathrm{~s}$ \\
\hline
\end{tabular}

FIGURA 12. Porcentaje de placa bacteriana según número de superficies con código 
En una diapositiva presente el índice de Silness y Löe modificado, tal como lo muestra la figura 11.

\section{ODONTOGRAMA}

Para éste ítem, presente de manera gráfica el odontograma del paciente, además de los índices ceo-d y Cop-D, de acuerdo con las convenciones que se presentan en la tabla 6 .

TABLA 6. Convenciones del odontograma

\begin{tabular}{|l|l|}
\hline Hallazgo & Convenciones \\
\hline Caries & $\begin{array}{l}\text { Sombrear la superficie afectada } \\
\text { con rojo } \\
\text { o ionómero }\end{array}$ \\
\hline $\begin{array}{l}\text { Obturación en } \\
\text { amalgama }\end{array}$ & $\begin{array}{l}\text { Sombrear la superficie con } \\
\text { amarillo }\end{array}$ \\
\hline Extracción indicada & $\begin{array}{l}\text { Sombarear la superficie con azul } \\
\text { sobre el diente con extracción } \\
\text { indicada }\end{array}$ \\
\hline Sellante & $\begin{array}{l}\text { Dibuje la letra "s" de color negro } \\
\text { sobre la superficie }\end{array}$ \\
\hline En erupción & $\begin{array}{l}\text { Dibuje una flecha al lado distal } \\
\text { del diente que está en emergen- } \\
\text { cia, con dirección según sea el } \\
\text { caso }\end{array}$ \\
\hline
\end{tabular}

Fuente: elaboración propia

Después de elaborar el odontograma de su paciente, preséntelo gráficamente en una diapositiva como lo muestra la figura 13.

\section{ODONTOGRAMA}

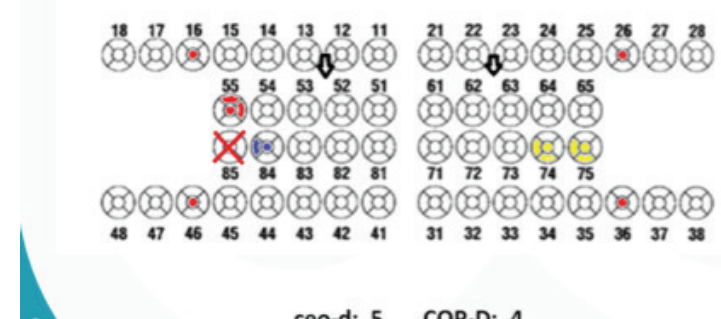

ceo-d: 5 COP-D: 4

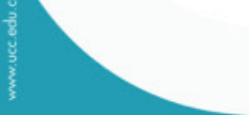

FIGURA 13. Odontograma

Fuente: Elaboración propia

\section{HALLAZGOS DENTALES: CRITERIOS ICDAS}

Con una fotografía intraoral de arco superior e inferior (ver figuras 15 y 16), describa los hallazgos encontrados en la valoración clínica de caries de su paciente en cada arco, de acuerdo con la codificación realizada por el sistema internacional para la detección y valoración de la caries (ICDAS, por sus siglas en inglés). En la figura 14 encontrará la doble codificación que utiliza el sistema ICDAs para presentar los hallazgos dentales.

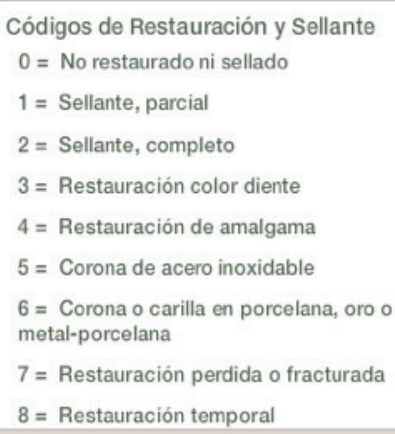

Para registrar enfermedad dental, usará el Sistema Internacional de Detección y Valoración de Caries (ICDAS).

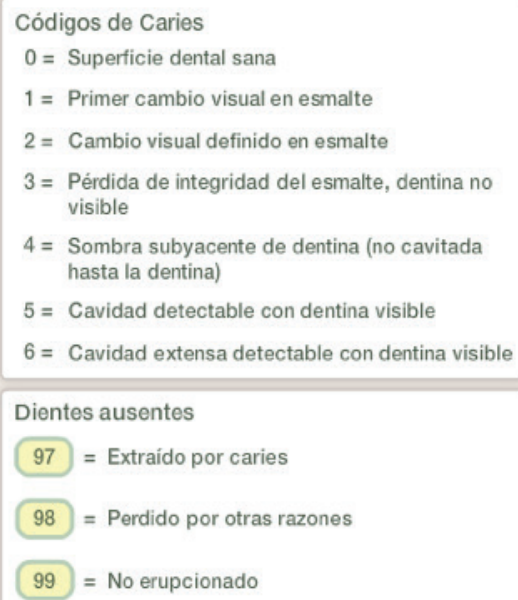

FIGURA 14. Sistema Internacional para la Detección y Valoración de Caries Dental (ICDAS) 


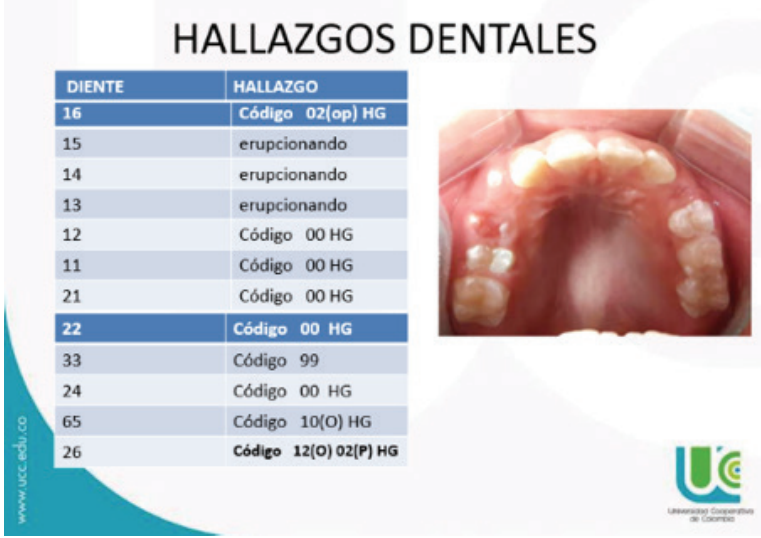

FIGURA 15. Hallazgos dentales arco superior

Fuente: elaboración propia

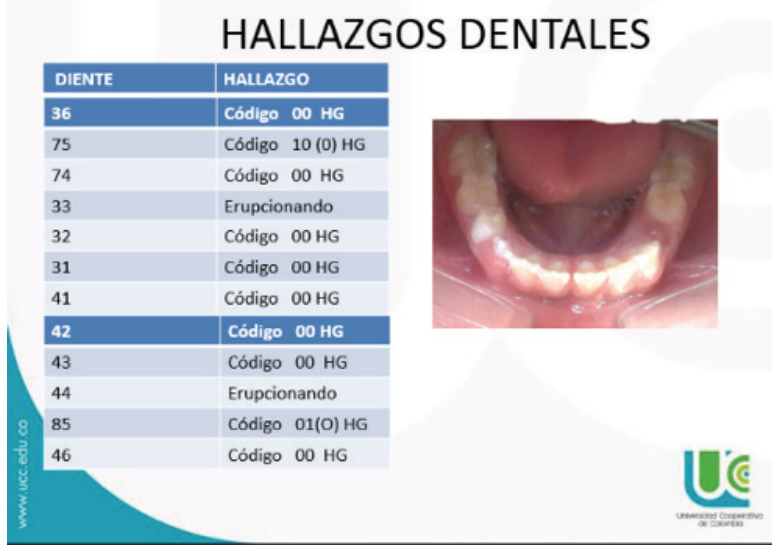

FIGURA 16. Hallazgos dentales arco inferior

Fuente: elaboración propia

\subsection{Otros hallazgos dentales}

Este ítem se debe presentar en diapositivas con fotografías de arco superior e inferior y también de lado derecho e izquierdo, para determinar características interarco e intraarco que permitan reconocer alteraciones en la oclusión. Las siguientes características se deben registrar como lo presentan las figuras de la 17 a la 21:

- Anomalías de posición: rotaciones, versiones, gresiones

- Forma de arco: superior e inferior
- Espacios del primate: superior e inferior (dentición temporal)

- Clase canina: derecha e izquierda según tipo de dentición

- Escalón o clase molar: derecha e izquierda, teniendo en cuenta el tipo de dentición

- Sobremordida: horizontal (overjet, $\mathrm{mm}$ ) y vertical (overbite, \% y mm)

Nota: Las fotografías pueden ir acompañadas de fotografías de modelos, siempre y cuando estos se encuentren formaleteados.

\section{HALLAZGOS DENTALES}

- FORMA DE ARCO: oval

- anomalías POSICIÓN: VV 13

- eSPACIOS DEL PRIMATE: No aplica.
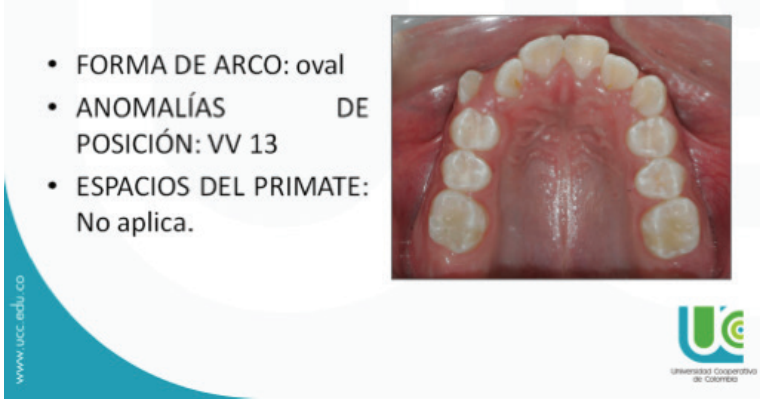

FIGURA 17. Análisis intraarco superior

Fuente: elaboración propia

\section{HALLAZGOS DENTALES}

- FORMA DE ARCO: oval

- anomalías POSICIÓN: VV 13

- eSPACIOS DEL PRIMATE: No aplica.

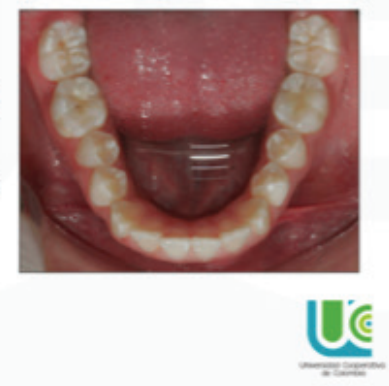

FIGURA 18. Análisis intraarco inferior

Fuente: elaboración propia 


\section{HALLAZGOS DENTALES}

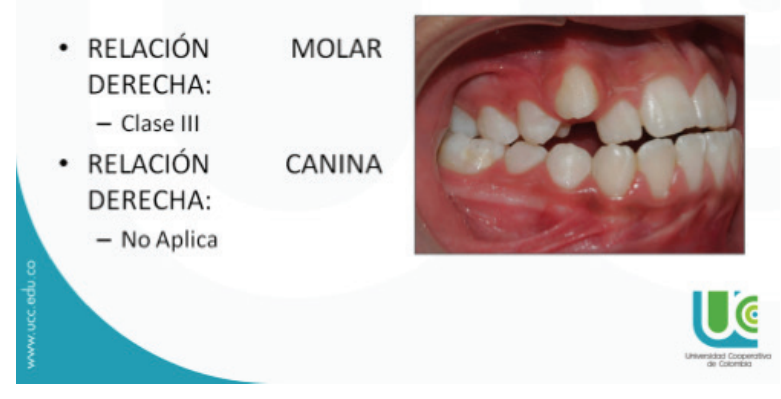

FIGURA 19. Análisis interarco derecho

Fuente: elaboración propia

\section{HALLAZGOS DENTALES}

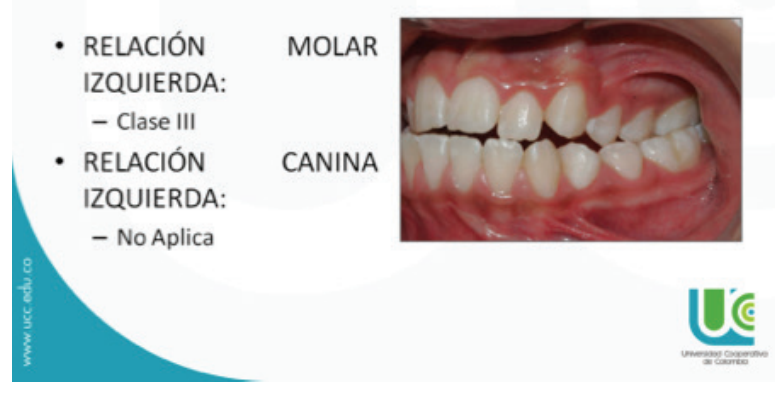

FIGURA 20. Análisis interarco izquierdo

Fuente: Elaboración propia

\section{HALLAZGOS DENTALES}

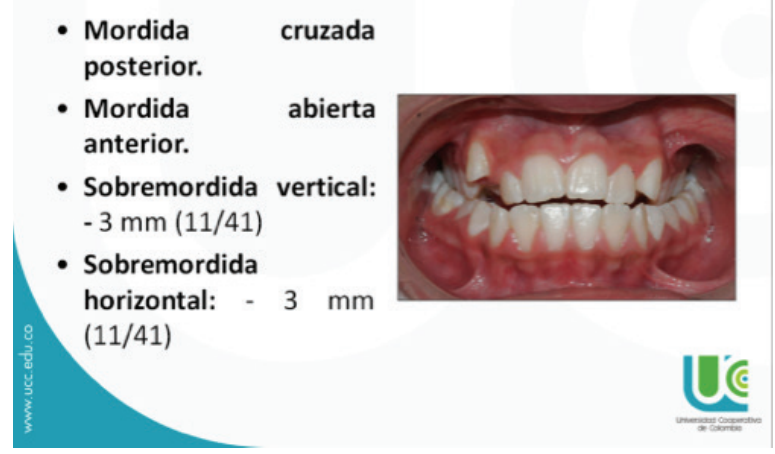

FIGURA 21. Análisis oclusión de frente

Fuente: Elaboración propia

\section{VALORACIÓN DE RIESGO INDIVIDUAL DE CARIES CON RIESGOGRAMA}

La caries dental es una enfermedad reemergente [9], compleja, dinámica y crónica, causada por eventos metabólicos de la biopelícula que recubre el tejido dental, lo que provoca la pérdida de equilibrio entre el mineral dental y el fluido de la biopelícula, y causa disolución química [10].

Por lo anterior, es importante contar con concentraciones mínimas de flúor en boca para mitigar los procesos de desmineralización. Existen otros factores de riesgo que aumentan la posibilidad de desarrollar caries junto con la disolución ácida como la frecuente ingesta de carbohidratos, bajos niveles de flujo salivar, experiencia de caries medidas con el índice cop-dental y factores socioeconómicos, entre otros [11].

Para la valoración de riesgo individual de caries existen diversas herramientas como el método CAMBRA (Caries Management by Risk Assessment) o el programa Cariogram $®$. Sin embargo, estas son poco aplicadas en nuestro medio. Esto llevó al grupo de expertos de Téllez y colaboradores [11] a diseñar e implementar el riesgograma, una versión modificada del Cariogram ${ }^{\circledR}$ para fomentar la prevención de lesiones nuevas de caries en los pacientes colombianos. El riesgograma es un método mediante el cual se evalúan siete factores de riesgo del paciente:

1. Experiencia de caries (COP-D, Ceo-d, ceo-d + CoP-D, con puntajes de 0, 10, 20).

2. Presencia de placa bacteriana mediante el índice de Silness y Löe (anotando las medianas).

3. Retención de placa sistémica o local (no retención $=0$ y presencia $=1$ )

4. Uso de crema dental con flúor (mínimo dos veces al día $=0$, menos de dos veces al día $=10$, no uso $=20$ ). 
5. Frecuencia de ingesta diaria (máximo siete comidas/día incluidos bebidas y pasabocas $=0$, más de siete veces $/$ día $=20$ ).

6. Número de veces de consumo de comidas altas en carbohidratos (máximo una porción/semana $=0$, más de una porción/ semana $=20$ ).

7. Motivo para la última visita odontológica (acceso adecuado: cita hace menos de un año por razones preventivas $=0$, acceso inadecuado: cita hace más de un año por razones de urgencia $=20$ ) [10].
Diligencie el riesgograma (ver figura 22) de acuerdo con los criterios antes mencionados, marcando la casilla según corresponda al caso de su paciente. Esto debe hacerse junto a la entrevista a los padres durante la anamnesis. Presente en una diapositiva el formato diligenciado.

En otra diapositiva presente el nivel de riesgo individual de caries con base en la sumatoria de los valores obtenidos en cada uno de los factores. Identifique la casilla que corresponda de acuerdo con la figura 23.

\begin{tabular}{|c|c|c|c|}
\hline \multicolumn{4}{|c|}{ VALORACION DE RIESGO DE CARIES DENTAL. } \\
\hline \multirow[t]{2}{*}{$\begin{array}{l}\text { Nombre: } \\
\text { Odontologo: }\end{array}$} & \multirow[t]{2}{*}{$\begin{array}{ll}\text { Edad: anos } \\
\text { Cludad: }\end{array}$} & \multirow[b]{2}{*}{ Puntaje } & \multirow[b]{2}{*}{$\begin{array}{l}\text { Total } \\
\text { Sector }\end{array}$} \\
\hline & & & \\
\hline $\begin{array}{l}\text { Experiencia de Caries } \\
(\text { ceo-d }+ \text { COP-D) }\end{array}$ & $\begin{array}{l}\text { ceo-d } \square \quad \text { COP/D } \square \text { ceo-d + COP-D } \square \\
=3 \text { lesiones cavitacionales: } \square\end{array}$ & $\square \square \square$ & \multirow{3}{*}{ \్ } \\
\hline $\begin{array}{l}\text { Indice de } \\
\text { Placa Bacteriana }\end{array}$ & Mediana = $0 \square$ & $\square \square \square$ & \\
\hline $\begin{array}{l}\text { Retención de Placa } \\
\text { Localizada o por } \\
\text { Compromiso Sistémico }\end{array}$ & $\begin{array}{l}\text { Sistémicos: } \\
\text { Localves: }\end{array}$ & $\square \square$ & \\
\hline $\begin{array}{l}\text { Contenido de } \\
\text { Carbohidratos } \\
\text { en la Dieta }\end{array}$ & $0-1$ porción/semana $\square>1$ porción/semana $\square$ & $\stackrel{0}{\square} \square^{10}$ & \\
\hline $\begin{array}{l}\text { Número de comidas / } \\
\text { pasabocas y/0 } \\
\text { bebidas / dia }\end{array}$ & $=7$ veces $/$ dia $\square$ & $\stackrel{0}{\square} \square^{10}$ & \\
\hline $\begin{array}{l}\text { Uso diario de } \\
\text { crema dental } \\
\text { con flúor }\end{array}$ & $\begin{array}{l}\text { Frecuencia: } \\
=2 \text { veces/dia } \square\end{array}$ & $\stackrel{0}{\square} \square^{20}$ & $\frac{\ddot{2}}{\frac{\pi}{8}}[$ \\
\hline $\begin{array}{l}\text { Acceso a consulta en el } \\
\text { cultimo año por motivo } \\
\text { differente a urgencia }\end{array}$ & $\begin{array}{l}\text { Asistió en el último año a consulta odontológica por } \\
\text { motivo diferente a urgencia } \\
\text { (diagnóstico, prevención, tratamiento): } \\
\qquad \text { SI } \square\end{array}$ & $\square$ & 总 \\
\hline & & RIESGO TOTAL & $\%$ \\
\hline
\end{tabular}

FIGURA 22. Formato de riesgograma

Fuente: [11]

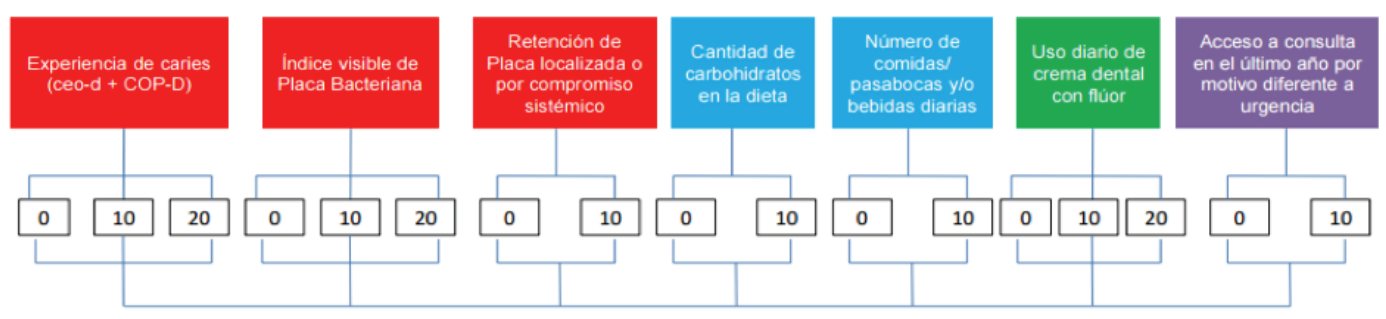

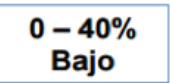

$-40 \%$
Bajo
$50-60 \%$

Mediano
$70-100 \%$

Alto

FIGURA 23. Nivel de riesgo individual de caries

Fuente: [12] 


\section{ANÁLISIS FUNCIONAL}

El análisis funcional del sistema estomatognático permite identificar la presencia de hábitos nocivos del paciente pediátrico que lleve a desarmonías oclusales y faciales. En esta diapositiva se debe presentar la exploración realizada de las funciones del sistema estomatognático siguiendo la tabla 7, que orienta la valoración y los resultados de la exploración:

TABLA 7. Análisis funcional del sistema estomatognático

\begin{tabular}{|l|l|}
\hline Valoración & Análisis \\
\hline Labios & $\begin{array}{l}\text { Presentan o no sellado labial, hiper o } \\
\text { hipotónicos. }\end{array}$ \\
\hline Lengua & $\begin{array}{l}\text { Movilidad adecuada, presencia de } \\
\text { anquiloglosia. }\end{array}$ \\
\hline Respiración & Nasal, oral, mixta. \\
\hline Deglución & Normal, atípica o infantil. \\
\hline Succión digital & Duración, intensidad y frecuencia. \\
\hline Onicofagia & Duración, intensidad y frecuencia. \\
\hline Otros & $\begin{array}{l}\text { Dislalias, bruxismo, mordedura de obje- } \\
\text { tos, succión lingual, etc. }\end{array}$ \\
\hline
\end{tabular}

Fuente: elaboración propia

\section{ANÁLISIS RADIOGRÁFICO}

A continuación, se exponen las principales radiografías usadas para el diagnóstico en el paciente pediátrico, utilizadas como ayudas complementarias en procura de realizar un análisis juicioso del caso del paciente que lleve a un plan de tratamiento más asertivo. Presente aquellas radiografías requeridas por el paciente según corresponda el caso (caries, ortopedia maxilar).

\subsection{Análisis radiografía periapical}

En una diapositiva presente las radiografías periapicales de su paciente con una descripción estructurada de los hallazgos encontrados en estas, tal como lo muestra la figura 24. Debe mencionar los dientes analizados e iniciar con la presentación de los hallazgos a nivel coronal (radiolucidez compatible con caries, radiopacidad compatible con restauración desbordante, etc.) y finalizar con la descripción de los hallazgos encontrados a nivel radicular (radiolucidez mesial a raíz distal de 36 compatible con lesión periapical, etc.).

\section{RADIOGRAFÍA PERIAPICAL}
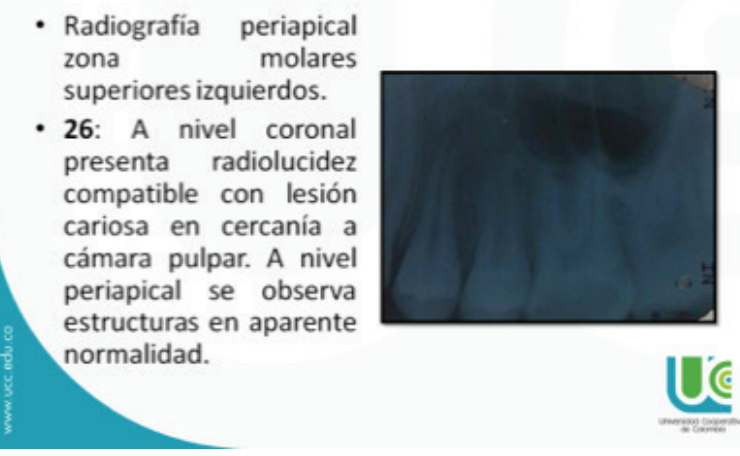

FIGURA 24. Análisis radiografía periapical

Fuente: elaboración propia

\subsection{Análisis radiografía coronal o de aleta de mordida}

Este tipo de radiografía es la más usada en la práctica de Odontopediatría y está indicada para la detección de caries interproximales cuando se observan clínicamente espacios interproximales muy estrechos en zona de molares [13]. En ella debe identificar los hallazgos a nivel coronal de todos los dientes presentados en la radiografía tales como la presencia de obturaciones o lesiones cariosas (ver figura 25).

\section{RADIOGRAFÍA CORONAL}

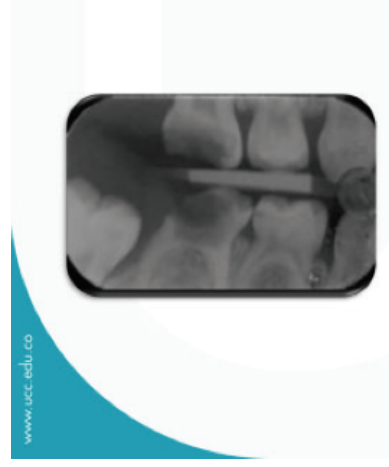

- Radiografía coronal lado derecho donde se observa:

- 84: radiolucidez a nivel coronal distal compatible con lesión cariosa.

- 85: radiolucidez a nivel coronal compatible con destrucción por caries, a nivel de furca radiolucidez compatible con lesión.

FIGURA 25. Análisis radiografía coronal

Fuente: elaboración propia 


\subsection{Análisis radiografía panorámica}

La radiografía panorámica es muy útil en el periodo de dentición mixta temprana, intertransicional y mixta tardía, pues puede determinar posibles alteraciones a nivel dental o de los maxilares y con base en ello plantear un adecuado tratamiento (ver figura 26). Durante la presentación hay que identificar las cinco regiones anatómicas al momento de evaluar este tipo de radiografía:

- Región nasomaxilar: Identificar septum nasal, cornetes, meatos, senos maxilares.

- Región ATM: Identificar las estructuras de la ATM como la posición del cóndilo en la cavidad glenoidea, cabeza y cuello del cóndilo, escotadura sigmoidea y apófisis coronoides.

- Región dentición superior: Identificar los diferentes estadios según Nolla de la dentición como también vías de erupción, anomalías de estructura o número, quistes o tumores odontogénicos, etc.

- Región dentición inferior: Identificar los diferentes estadios según Nolla de la dentición, como también vías de erupción, anomalías de estructura o número, quistes o tumores odontogénicos, etc.

- Región mandibular: Identificar trabeculado óseo, escotadura antegonial, si se encuentran o no simetrías en cuerpo, rama o cóndilo de la mandíbula.

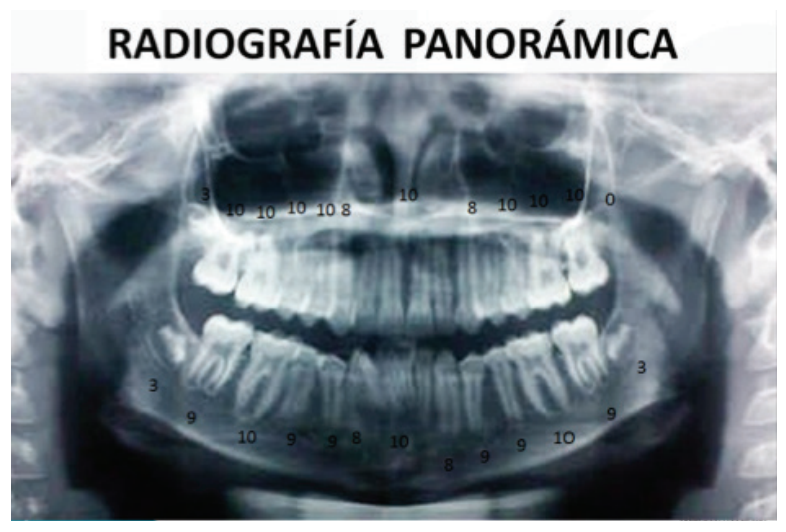

FIGURA 26. Radiografía panorámica

Fuente: Elaboración propia
14.4. Análisis radiografía lateral de cráneo La radiografía de perfil o lateral de cráneo es útil para observar los cambios durante el crecimiento y el desarrollo activo del paciente, así como los cambios terapéuticos con procedimientos de ortodoncia, ortopedia maxilar o cirugía ortognática. Además, permite relacionar espacialmente las bases óseas (maxilar y mandíbula) con respecto a la base del cráneo, el tamaño de las bases óseas y la posición de los dientes en los maxilares [14]. Para el caso clínic, debe presentar la radiografía junto con los trazos cefalométricos para evaluar los resultados del análisis de Steiner y McNamara (ver figuras 27 y 28). Para hacer los análisis cefalométricos remitase al segundo capítulo del libro del Dr. Gonzalo Uribe, Ortodoncia: teoría y clínica [6].

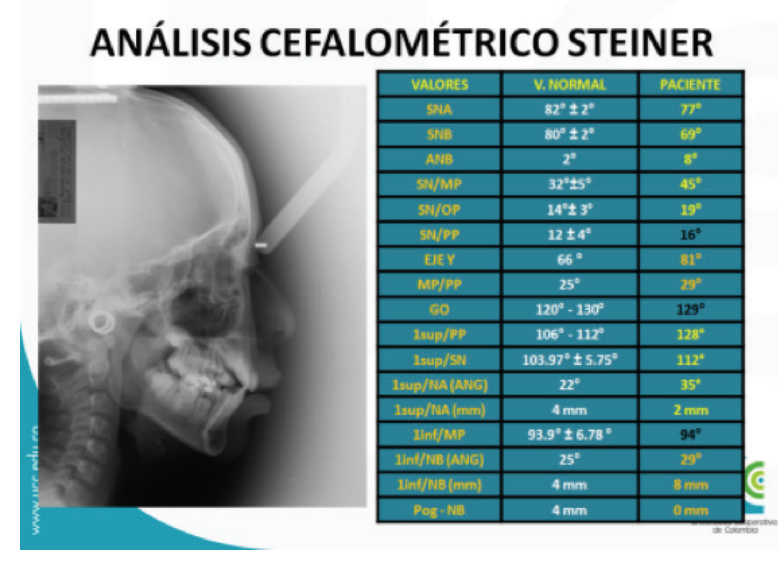

FIGURA 27. Análisis cefalométrico de Steiner

Fuente: elaboración propia

\section{ANÁLISIS CEFALOMÉTRICO MCNAMARA}

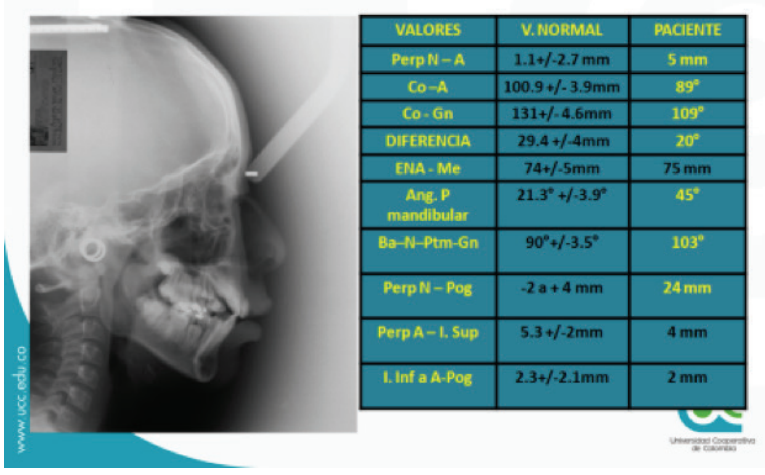

FIGURA 28. Análisis cefalométrico de McNamara

Fuente: elaboración propia 


\section{ANÁLISIS DE DENTICIÓN MIXTA}

El análisis de dentición mixta es un método de diagnóstico que permite predecir la anchura mesiodistal de caninos y premolares antes de emerger en boca, comparar esta medida con el espacio disponible para su erupción y evaluar la disponibilidad de espacio que presente el sector incisivo de los arcos dentales, con lo que ayuda a establecer pautas para el manejo de espacios en dentición mixta [15].

Para hacer el análisis de dentición mixta de Moyers se requiere de los modelos de estudio de su paciente, un compás de puntas secas o calibrador metálico, regla y lápiz. A continuación, tome la distancia mesiodistal de los cuatro incisivos inferiores permanentes (32-3141-42) y súmelos. Después, revise las tablas de predicciones de Moyers de tamaños esperados de caninos y premolares según maxilar que se analiza (superior o inferior) y el sexo del paciente.

Moyers sugiere que el percentil para ubicar el tamaño de caninos y premolares (espacio requerido) sea de 75 (ver figuras 29 y 30). Anote el valor encontrado y luego proceda a medir el "espacio disponible", que lo toma desde la zona gingival mesial de canino temporal a distal de segundo molar temporal. El siguiente paso es determinar la diferencia entre espacio disponible y espacio requerido. El valor que acaba de obtener es el espacio disponible del sector posterior.

Para el sector anterior mida el espacio de incisivo central y lateral en su parte gingival, luego determine la anchura mesiodistal de cada incisivo y súmelas. Al obtener los dos resultados calcule su diferencia y con esto obtiene el espacio disponible del sector anterior. Con base estos resultados, se puede diagnosticar y realizar un manejo de espacios de la dentición mixta.

Presente en una diapositiva los valores totales por hemiarcada y el plan de manejo de espacio sugerido (mantener espacio, reganar espacio, supervisar espacio, grandes discrepancias).

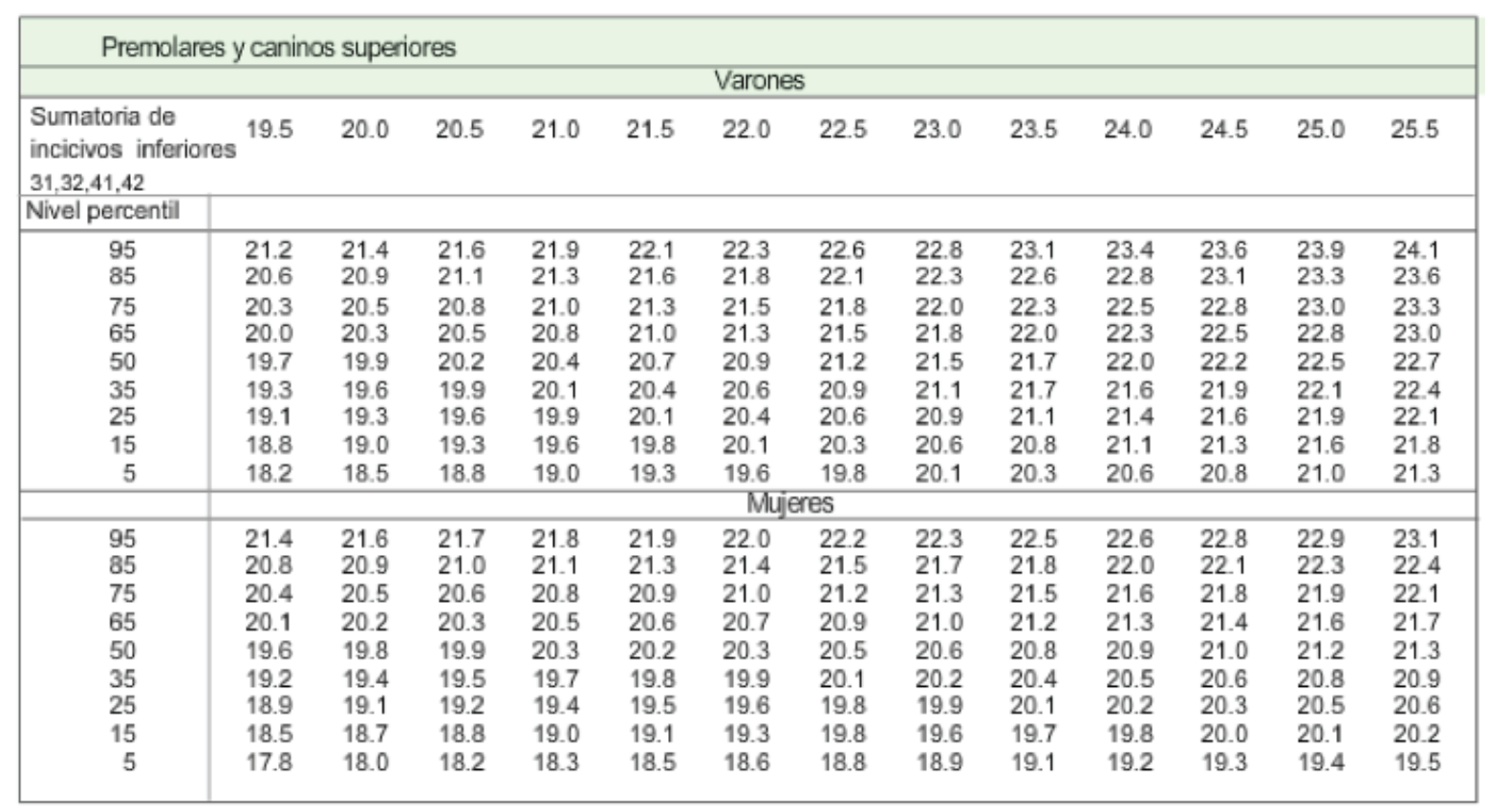

FIGURA 29. Tabla de predicción de tamaño mesiodistal de caninos y premolares superiores 


\begin{tabular}{|c|c|c|c|c|c|c|c|c|c|c|c|c|c|}
\hline \multicolumn{14}{|c|}{ Premolares y caninos inferiores } \\
\hline \multicolumn{14}{|c|}{ Varones } \\
\hline \begin{tabular}{|l} 
Sumatoria de \\
incicivos inferiores \\
$31,32,41,42$
\end{tabular} & 19.5 & 20.0 & 20.5 & 21.0 & 21.5 & 22.0 & 22.5 & 23.0 & 23.5 & 24.0 & 24.5 & 25.0 & 25.5 \\
\hline \multicolumn{14}{|l|}{ Nivel persentil } \\
\hline $\begin{array}{r}95 \\
85 \\
75 \\
65 \\
50 \\
35 \\
25 \\
15 \\
5\end{array}$ & $\begin{array}{l}21.6 \\
20.8 \\
20.4 \\
20.0 \\
19.5 \\
19.0 \\
18.7 \\
18.2 \\
17.5\end{array}$ & $\begin{array}{l}21.8 \\
21.0 \\
20.6 \\
20.2 \\
19.7 \\
19.3 \\
18.9 \\
18.5 \\
17.7\end{array}$ & $\begin{array}{l}22.0 \\
21.2 \\
20.8 \\
20.4 \\
20.0 \\
19.5 \\
19.1 \\
18.7 \\
18.0\end{array}$ & $\begin{array}{l}22.2 \\
21.4 \\
21.0 \\
20.6 \\
20.2 \\
19.7 \\
19.4 \\
18.9 \\
18.2\end{array}$ & $\begin{array}{l}22.4 \\
21.6 \\
21.2 \\
20.9 \\
20.4 \\
20.0 \\
19.6 \\
19.2 \\
18.5\end{array}$ & $\begin{array}{l}22.6 \\
21.9 \\
21.4 \\
21.1 \\
20.6 \\
20.2 \\
19.8 \\
19.4 \\
18.7\end{array}$ & $\begin{array}{l}22.8 \\
22.1 \\
21.6 \\
21.3 \\
20.9 \\
20.4 \\
20.1 \\
19.6 \\
18.9\end{array}$ & $\begin{array}{l}23.0 \\
22.3 \\
21.9 \\
21.5 \\
21.1 \\
20.6 \\
20.3 \\
19.9 \\
19.2\end{array}$ & $\begin{array}{l}23.2 \\
22.5 \\
22.1 \\
21.8 \\
21.3 \\
20.9 \\
20.5 \\
20.1 \\
19.4\end{array}$ & $\begin{array}{l}23.5 \\
22.7 \\
22.3 \\
22.0 \\
21.5 \\
21.1 \\
20.7 \\
20.3 \\
19.6\end{array}$ & $\begin{array}{l}23.7 \\
23.0 \\
22.5 \\
22.2 \\
21.7 \\
21.3 \\
21.0 \\
20.5 \\
19.8\end{array}$ & $\begin{array}{l}23.9 \\
23.2 \\
22.8 \\
22.4 \\
22.0 \\
21.5 \\
21.2 \\
20.7 \\
20.0\end{array}$ & $\begin{array}{l}24.2 \\
23.4 \\
23.0 \\
22.7 \\
22.2 \\
21.7 \\
21.4 \\
20.9 \\
20.2\end{array}$ \\
\hline \multicolumn{14}{|c|}{ Mujeres } \\
\hline 95 & 20.8 & 21.0 & 21.2 & 21.5 & 21.7 & 22.0 & 22.2 & 22.5 & 22.7 & 23.0 & 23.3 & 23.6 & 23.9 \\
\hline 85 & 20.0 & 20.3 & 20.5 & 20.7 & 21.0 & 21.2 & 21.5 & 21.8 & 22.0 & 22.3 & 22.6 & 22.8 & 23.1 \\
\hline 75 & 19.6 & 19.8 & 20.1 & 20.3 & 20.6 & 20.8 & 21.1 & 21.3 & 21.6 & 21.9 & 22.1 & 22.4 & 22.7 \\
\hline 65 & 19.2 & 19.5 & 19.7 & 20.0 & 20.2 & 20.5 & 20.7 & 21.0 & 21.3 & 21.5 & 21.8 & 22.1 & 22.3 \\
\hline 50 & 18.7 & 19.0 & 19.2 & 19.5 & 19.8 & 20.0 & 20.3 & 20.5 & 20.8 & 21.1 & 21.3 & 21.6 & 21.8 \\
\hline 35 & 18.2 & 18.5 & 18.8 & 19.0 & 19.3 & 19.6 & 19.8 & 20.1 & 20.3 & 20.6 & 20.9 & 21.1 & 21.4 \\
\hline 25 & 17.9 & 18.1 & 18.4 & 18.7 & 19.0 & 19.2 & 19.5 & 19.7 & 20.0 & 20.3 & 20.5 & 20.8 & 21.0 \\
\hline 15 & 17.4 & 17.7 & 18.0 & 18.3 & 18.5 & 18.8 & 19.1 & 19.3 & 19.6 & 19.8 & 20.1 & 20.3 & 20.6 \\
\hline 5 & 16.7 & 17.0 & 17.2 & 17.5 & 17.8 & 18.1 & 18.3 & 18.6 & 18.9 & 19.1 & 19.3 & 19.6 & 19.8 \\
\hline
\end{tabular}

FIGURA 30. Tabla de predicción de tamaño mesiodistal de caninos y premolares inferiores

Fuente: [15]

\section{DIAGNÓSTICOS}

De acuerdo con la valoración clínica y radiográfica exhaustiva de su paciente elabore una tabla de diagnósticos presentándolos de manera descendente, desde lo general o macro hasta lo particular o micro, con base en la tabla 8.

TABLA 8. Hoja de diagnósticos

\begin{tabular}{|l|l|}
\hline Diagnósticos & \\
\hline Sistémico & $\begin{array}{l}\text { Según lo referido en la revisión por sistemas: dis- } \\
\text { crasias sanguíneas, asma, hipertiroidismo, etc. }\end{array}$ \\
\hline Psicosocial & $\begin{array}{l}\text { De acuerdo con la dinámica familiar y social del } \\
\text { paciente: alto, medio o bajo riesgo. }\end{array}$ \\
\hline Craneal & Dolicocéfalo, braquicéfalo, mesocéfalo. \\
\hline Facial & Leptoprosopo, euriprosopo, mesoprosopo. \\
\hline Funcional & $\begin{array}{l}\text { Onicofagia, bruxismo, succión digital, incompe- } \\
\text { tencia labial, etc. }\end{array}$ \\
\hline Periodontal & Gingivitis asociada a placa bacteriana. \\
\hline Oclusal & $\begin{array}{l}\text { Mordidas cruzadas, abiertas, profundas, malposi- } \\
\text { ciones dentales, pérdidas de espacio. }\end{array}$ \\
\hline Pulpar & Pulpitis, periodontitis, abscesos. \\
\hline Dental & $\begin{array}{l}\text { Caries coronal primaria o secundaria, fluorosis, } \\
\text { amelogenesis, etc. }\end{array}$ \\
\hline
\end{tabular}

Fuente: elaboración propia

\section{PRONÓSTICO}

Con base en los diagnósticos y la actitud del paciente y la del acudiente, determine el pronóstico de las patologías halladas que pueden llevar al éxito o al fracaso del posible plan de tratamiento. De acuerdo con lo anterior, clasifíquelo en "Bueno", "Favorable", "Malo" o "Reservado". Puede realizarlo general o individual según sus diagnósticos.

\section{PLAN DE TRATAMIENTO}

El plan de tratamiento debe ejecutarse de tal manera que se resuelva el motivo de consulta por el que acudió el paciente, categorizándolo según el riesgo encontrado [16, 17]. Recuerde que el tratamiento se realiza de manera integral atendiendo todas las esferas del niño (biológica, médica, social) (ver tabla 9 y figura 29). A continuación, presente el conjunto de medidas escogidas para su paciente que llevaron a la eliminación o modificación de factores de riesgo para la presencia de las patologías halladas, a la promoción de la salud oral, al 
tratamiento operatorio y ortopédico; así como a las interconsultas con especialistas como pediatras, psicólogos, fonoaudiólogos, otorrinolaringólogos, etc. El plan de tratamiento se elabora con base en el cuadro de diagnósticos elaborado antes.

TABLA 9. Categorización de plan de tratamiento según prioridad

\begin{tabular}{|c|c|}
\hline \multicolumn{2}{|l|}{ Plan de tratamiento en odontopediatría } \\
\hline $\begin{array}{l}\text { 1. Resolver urgencias } \\
\text { 2. Control de infección } \\
\text { 3. Controlar riesgo de reinfección } \\
\text { 4. Reforzar el huésped } \\
\text { 5. Controlar el medio patogénico } \\
\text { 6. Orientar la corrección de hábitos }\end{array}$ & Alta básica \\
\hline $\begin{array}{l}\text { 1. Resolver problemas pulpares } \\
\text { 2. Resolver problemas periodontales } \\
\text { 3. Resolver problemas mucosos } \\
\text { 4. Restaurar unidad diente } \\
\text { 5. Orientar la corrección de hábitos }\end{array}$ & Alta intermedia \\
\hline $\begin{array}{l}\text { 1. Resolver problemas protésicos } \\
\text { 2. Interceptar o corregir problemas de oclusión } \\
\text { 3. Resolver problemas en niños con riesgo } \\
\text { médico }\end{array}$ & Alta integral \\
\hline
\end{tabular}

Fuente: [16]

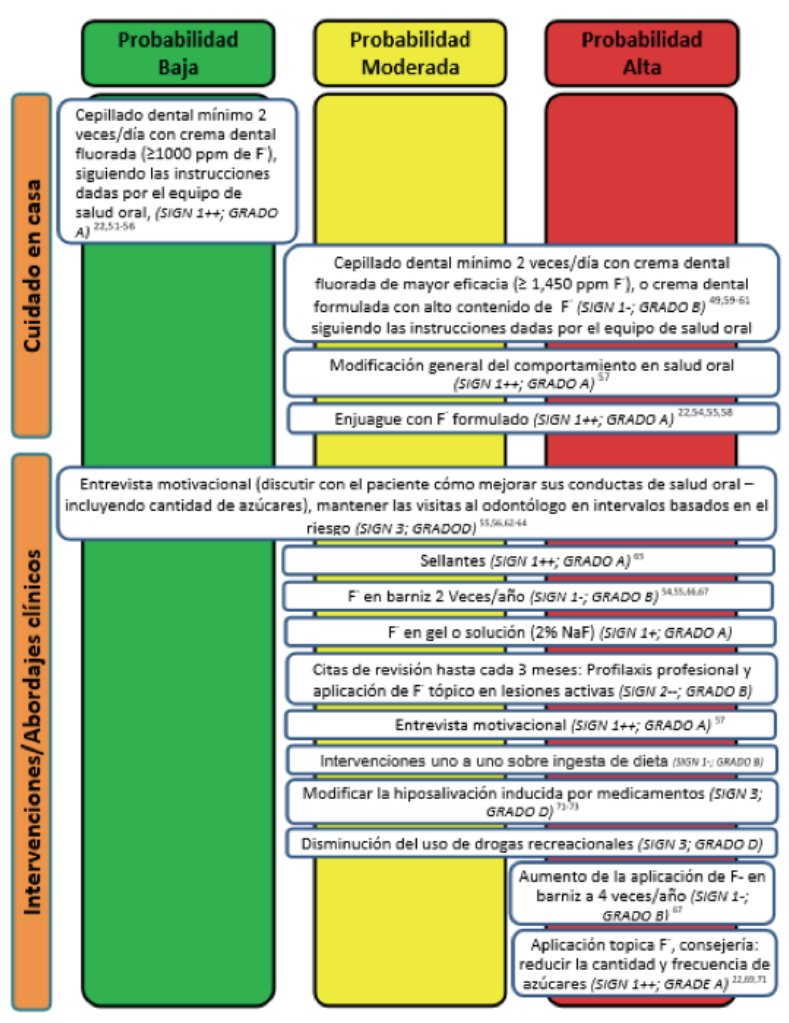

FIGURA 31. Manejo de factores de riesgo

Fuente: [17]

\section{REVISIÓN DEL TEMA}

Después de hacer la presentación del caso clínico de su paciente y de acuerdo con el hallazgo más relevante encontrado como antecedentes médicos, aspectos funcionales u oclusales y tratamiento realizado, etc., presente ese tema relevante a través de una búsqueda de información científica (artículos, libros), de donde obtenga un argumento o criterio válido que lleve al manejo indicado del paciente. En las diapositivas, debe presentar las referencias bibliográficas de su búsqueda. Las pautas básicas para presentar el tema son las siguientes:

- Definición

- Historia (en caso de patologías sistémicas o aparatología)

- Epidemiología (en caso de patologías sistémicas)

- Manifestaciones orales (en caso de patologías sistémicas)

- Manejo odontológico (en caso de patologías sistémicas)

- Indicaciones, contraindicaciones (en caso de aparatología o tratamiento operatorio)

- Ventajas y desventajas (en caso de aparatología)

Este punto es el más importante de la presentación del caso clínico, pues se evalúa la rigurosidad de la búsqueda de información para enseñar al estudiante la argumentación de casos respaldados con literatura científica. 


\section{REFERENCIAS}

[1] Alvarado-Bestene J. Introducción a la clínica. Bogotá: Universidad Javeriana; 2003.

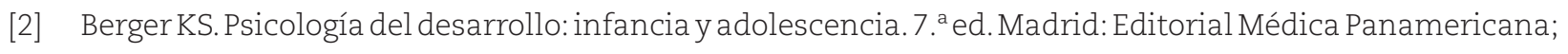
2007.

[3] Méndez-Castellano H, De Méndez MC. Estratificación social y biología humana: método Graffar modificado. Arch Venez Pueric Pediatr. 1986;49(3/4): 93-104.

[4] Méndez-Castellano H, De Méndez MC. Sociedad y estratificación. Caracas: Fundacredesa; 1994.

[5] Graber LW, Vanarsdall RL, Vig KWL. Ortodoncia: principios y técnicas actuales. 5. a ed. Barcelona: Editorial Elsevier; 2012.

[6] Burgué-Cedeño J. La cara, sus proporciones estéticas [internet]. s. f. Disponible en: http://www.sld.cu/ galerias/pdf/sitios/protesis/la_cara,_sus_proporciones_esteticas.pdf

[7] Ustrell Torrenti JM. Von Arx, JD. Ortodoncia. 2. ${ }^{a}$ ed. Barcelona: Publicaciones y Ediciones de la Universitat de Barcelona; 2002.

[8] Secretaría Distrital de Salud. Guía de Práctica Clínica en Salud Oral. Higiene Oral. Bogotá: Secretaría Distrital de Salud; 2010.

[9] Petersen PE. Sociobehavioural risk factors in dental caries-international perspectives. Community Dent and Oral Epidemiol. 2005; 38: 182-91.

[10] Marsh PD, Nyvad B. The oral microflora and biofilms on the teeth. En: Fejerskov O, Kidd E, ed. Dental caries: the disease and its clinical management. ${ }^{\text {nd }}$ ed. Singapore: Blackwell Munksgaard; 2008. p. 164-87.

[11] Téllez M, Martignon S, Cortés AP, Gómez HF. Valoración de riesgo individual de caries con el riesgograma. Ustasalud. 2009; 8:69-74.

[12] Pardo C. Rol de los factores psicosociales en los sistemas más representativos de evaluación individual de riesgo para desarrollar caries [tesis especialización]. [Bogotá]: Universidad Nacional de Colombia; 2014.

[13] Boj JR, Catalá M, García-Ballesta C, Mendoza A. Odontopediatría. Barcelona: Editorial Masson; 2004.

[14] Uribe G. Ortodoncia: teoría y clínica. Medellín: Centro de Investigaciones Biológicas; 2004.

[15] Yezioro S. Análisis de dentición mixta. Curso virtual Universidad Nacional de Colombia [internet]. 2013 [citado 2017 feb 19]. Disponible en: http://168.176.60.11/cursos/odontologia/denticion/index.html

[16] Bordoni N, Escobar A, Castillo R. Odontología pediátrica: la salud bucal del niño y el adolescente en el mundo actual. Buenos Aires: Editorial Médica Panamericana; 2010.

[17] Pitts N, Ismail AI, Martignon S, Ekstrand K, Douglas GVA, Longbottom C. Guía ICCMS ${ }^{\text {TM }}$ para clínicos y educadores. Londres: ICDAS Foundation; 2014. 


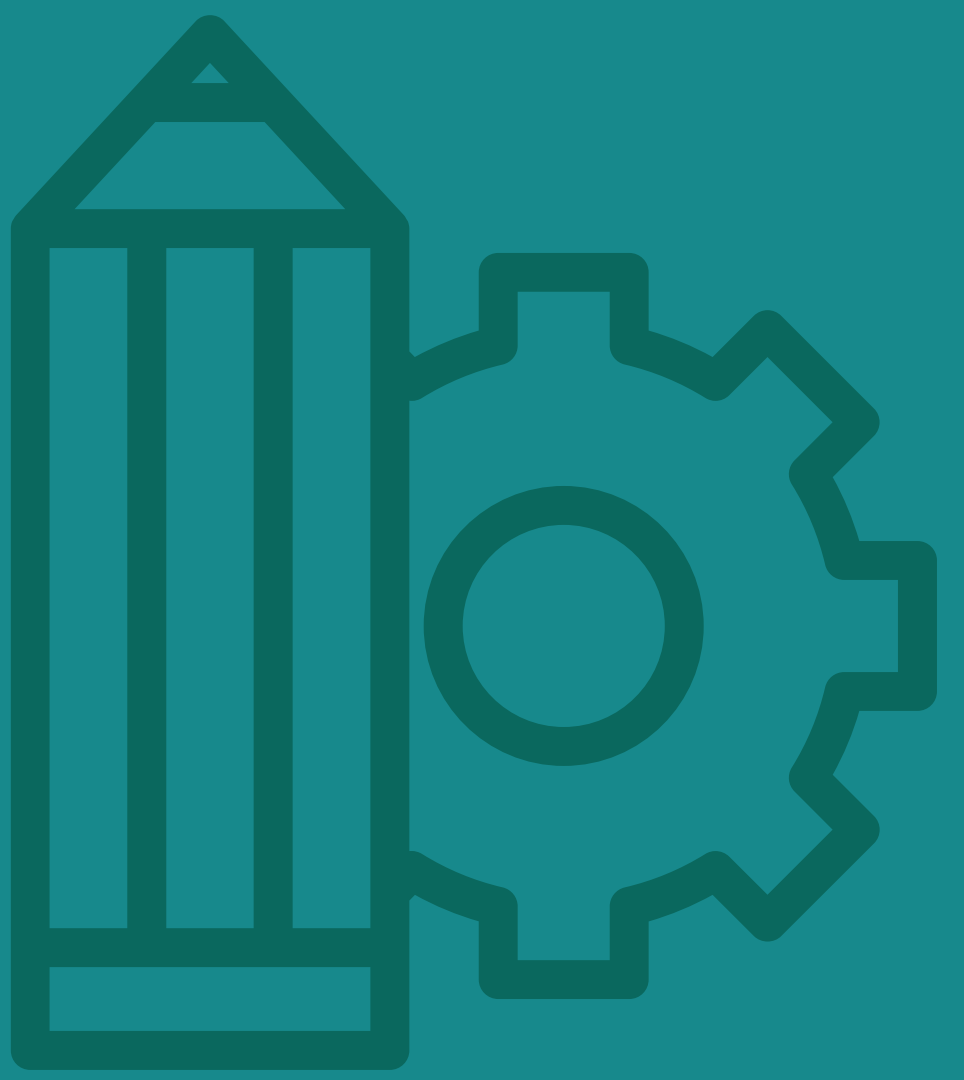

